\title{
A constitutive model for unsaturated soils: thermomechanical and computational aspects
}

\author{
D. Sheng, S. W. Sloan, A. Gens
}

\begin{abstract}
This paper first presents a complete formulation of a constitutive model that deals with the irreversible behaviour of unsaturated soils under various loading and drying/wetting conditions. A standard form of incremental stress-strain relations is derived. The constitutive model is then cast into the thermodynamical theories and verified using the thermomechanical principles. It is shown that hydraulic hysteresis does not contribute to the plastic dissipation, though it contributes to the plastic work. All plastic work associated with a plastic increment of the degree of saturation is stored and can be recovered in a reversed plastic increment of saturation. The incremental constitutive equations are also reformulated for implementation in finite element codes where displacements and pore pressures are primary unknowns. Qualitative predictions of the constitutive model show that incorporating two suction related yield surfaces and non-associated flow rules into the Barcelona Basic Model opens a full range of possibilities in modelling unsaturated soil behaviour.
\end{abstract}

Keywords Constitutive modelling, Unsaturated soils, Thermodynamics, Finite element method

\section{1}

\section{Introduction}

Elastoplastic constitutive modelling for unsaturated soils was pioneered by the work of Alonso et al. (1987) and Gens et al. (1989), which led to the complete formulation of an elastoplastic model by Alonso et al. (1990). Since then, a great number of constitutive models have been proposed (see Gens, 1996; Wheeler and Karube, 1996; Shen, 1998; for review). These models, though using different experimental curves for the soil behaviour and presented in different stress spaces, largely fall in the same framework of Alonso et al. (1990) and can be considered as its variants. The model by Alonso et al. (1990), which is later referred to as

Received: 27 May 2003 / Accepted: 5 December 2003

Published online: 5 February 2004

D. Sheng $(\bowtie)$, S. W. Sloan

School of Engineering,

The University of Newcastle,

NSW, 2308, Australia

E-mail: Daichao.Sheng@newcastle.edu.au

A. Gens

Civil Engineering School,

Technical University of Catalonia (UPC),

Barcelona, Spain the Barcelona basic model (BBM), remains one of the fundamental models for unsaturated soils.

The BBM and its variants all use a load-collapse yield surface that defines the variation of the yield surface along the suction axis. With this load-collapse yield surface they are able to reproduce some basic features of unsaturated soil behaviour. These basic features include e.g. elastoplastic volume decrease (collapse) upon wetting or upon isotropic compression, change of stiffness and shear strength with suction, moderate volume increase upon wetting. The last feature is modelled only as an elastic process in the BBM and its variants. Irreversible changes in volume and in degree of saturation upon wetting, or irreversible change in degree of saturation upon drying, can, however, not be modelled by the BBM or its variants.

In an attempt to model the observed irreversible swelling upon wetting of swelling soils, Gens and Alonso (1992) proposed conceptual modifications to the BBM. By combining microstructural behaviour of expansive minerals and macrostructural behaviour of large scale soil structures, the extended framework can qualitatively reproduce the large irreversible swelling upon wetting of swelling soils. At microstructural level the clay packets or elementary particle arrangements are assumed to be saturated and hence the microstructural deformation is governed by the effective stress principle. A neutral loading line that separates stress paths causing swelling from stress paths causing compression, is defined in the space of net mean stress versus suction. Stress paths causing microstructural swelling will also cause a softening of the load-collapse yield surface. Therefore, the neutral loading line is also a yield surface for the macrostructural behaviour. The conceptual model of Gens and Alonso (1992) was further developed to a mathematically complete model by Alonso et al. (1999). Two additional yield surfaces, one for plastic yielding caused by suction increase (SI) and the other by suction decease (SD), were introduced. These surfaces are parallel to the neutral loading line in the space of net mean stress versus suction, and are coupled to the LC surface through two experimentally determined functions. The model by Alonso et al. (1999) is able to predict the irreversible expansion caused by wetting at low stresses and shrinkage at high stresses. The irreversible change of degree of saturation during cyclic wetting and drying was not considered in the model of Gens and Alonso (1992) or of Alonso et al. (1999).

Recently Vaunat et al. (2000) presented a constitutive model that addresses the irreversible behaviour of unsaturated soils upon wetting and drying, in particular the 
so-called hydraulic hysteresis. The model is built on the BBM, but incorporates two additional yield surfaces derived from hydraulic hysteresis. One yield surface defines the plastic changes in the water content during drying (suction increase) and the other during wetting (suction decrease). These two yield surfaces are coupled as the movement of one will cause the movement of the other, but not coupled with load-collapse yield surface. By incorporating the suction-increase and suction-decrease yield surfaces with hydraulic hysteresis, this model is able to predict the irreversible change of degree of saturation during cyclic wetting and drying.

Very recently, Wheeler et al. (2003), based on Buisson and Wheeler (2000), presented an elastoplastic constitutive model that fully couples hydraulic hysteresis with the mechanical behaviour of the unsaturated soil. By appropriately choosing the stress variables, Wheeler et al. (2003) suggested that the load-collapse yield surface can be simplified to a vertical straight line in the space of the Bishop mean stress versus suction, and the suction-increase and suction-decrease yield surfaces arising from hydraulic hysteresis can be simplified to horizontal straight lines in the same space. The three yield surfaces are fully coupled with one another, as the movement of one will cause movement of the other two. This model is also able to predict some irreversible behaviour of unsaturated soils and will be discussed in this

This paper first presents constitutive model for unsat recent developments in the fie is then studied in the framew principles. The incrementa. reformulated for implementation in finite element codes where displacements and pore pressures are primary

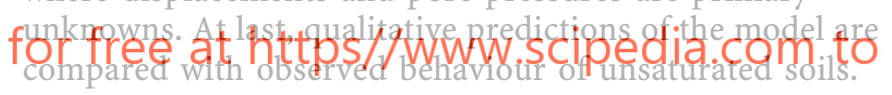

\section{2}

\section{Constitutive model}

The signs used in this paper follow the convention of soil mechanics, with positive stresses and strains in compression and contraction.

\section{1}

\section{Work-conjugate stress and strain variables}

One inevitable issue in modelling unsaturated soils is the choice of stress variables to work with, as it is no longer possible to identify one single stress variable (as the effective stress for saturated soils) for describing unsaturated soil behaviour. The debate has become less intense since Houlsby (1997) first showed that any adequate set of work-conjugate stresses and strains can be used for constitutive modelling of unsaturated soils. Neglecting the work dissipated by flow of pore fluids, Houlsby (1997) showed that the rate of work input per unit volume of unsaturated soil is

$$
\begin{aligned}
\dot{W}= & \left(\sigma_{i j}-S_{\mathrm{r}} \delta_{i j} u_{\mathrm{w}}-\left(1-S_{\mathrm{r}}\right) \delta_{i j} u_{\mathrm{a}}\right) \dot{\varepsilon}_{i j} \\
& +n s \dot{S}_{\mathrm{r}}+n\left(1-S_{\mathrm{r}}\right) u_{\mathrm{a}} \frac{\dot{\rho}_{\mathrm{a}}}{\rho_{\mathrm{a}}}
\end{aligned}
$$

where $W$ is the work input per unit volume of soil, $\sigma_{i j}$ is the total stress tensor, $\varepsilon_{i j}$ is the soil skeleton strain tensor, $S_{r}$ is the degree of saturation of water, $\delta_{i j}$ is the Kronecker delta, $u_{w}$ is the pore water pressure, $u_{a}$ is the pore air pressure, $n$ is the porosity, $s$ is the suction and

$s=u_{a}-u_{w} \rho_{a}$ is the density of pore air, and superior dot denotes the rate.

Neglecting the term for air compressibility $\dot{\rho}_{\mathrm{a}}$, Eq. (1) indicates that the stress in the brackets (known as average stress or Bishop stress) is work-conjugate with the soil skeleton strain, while the suction is work-conjugate with the relative water content in the voids. The work input for deformation of the soil skeleton is controlled by an average stress and the soil skeleton strain. This is similar to the case of saturated soils where the soil skeleton strain is solely controlled by the effective stress (Houlsby, 1979). The work input for changing relative water content in the void for every unit volume of void space is $s \dot{S}_{\mathrm{r}}$ and this is independent of the soil skeleton strain. This work input times the porosity $n$ gives the work input per unit volume of soil. The interpretation here also applies to saturated soils where the contribution $s \dot{S}_{\mathrm{r}}$ to the work input becomes zero as the relative water content in the voids remains constant.

Alternatively Eq. (1) can be rearranged as

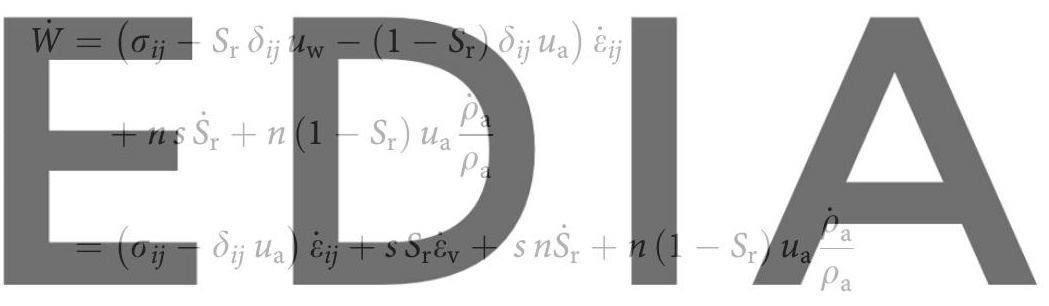

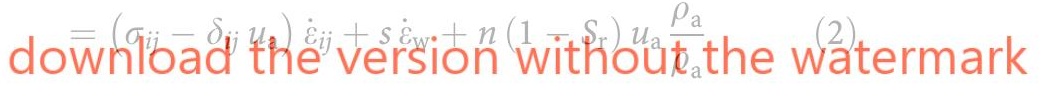

where $\dot{\varepsilon}_{\mathrm{W}}$ is the rate of a volumetric strain and $\varepsilon_{\mathrm{W}}=n S_{\mathrm{r}}$. Equation (2) indicates that the suction must be associated with $\varepsilon_{\mathrm{W}}$ if the net stress $\sigma_{i j}^{\prime \prime}=\sigma_{i j}-\delta_{i j} u_{\mathrm{a}}$ is associated with the soil skeleton strain. Vaunat et al. (2000) termed the strain quantity $\varepsilon_{\mathrm{w}}$ as the hydraulic strain. Again the above arrangement of work-conjugate stresses and strains is also valid for saturated soils where either $u_{a}$ is replaced by $u_{w}$ or $\dot{\varepsilon}_{\mathrm{W}}$ is replaced by $\dot{\varepsilon}_{\mathrm{v}}$ with $u_{\mathrm{a}}=0$.

While it is clear that any adequate set of work-conjugate stresses and strains can be used for constitutive modelling of unsaturated soils, the difference comes from the implementation of the constitutive models in finite element codes. When working with existing codes for saturated soils where most constitutive models are described in terms of effective stresses, the choice of the average stresses and suction as the stress variables is a natural extension to unsaturated soils. As the soil changes from unsaturated to saturated or vice-versa, the average stresses and the effective stresses are exchanged. All constitutive equations for unsaturated soils automatically recover those for saturated soils once the degree of saturation reaches one, and vice-versa when $S_{r}$ becomes less than one. This formulation is particularly convenient for analyses involving only pore water pressure, with pore air pressure assumed to be static. In such a case, the suction 
simply reduces to negative pore water pressure. No de-saturation suction for transition between saturated and unsaturated states is needed (Gens, 1996). It should be noted that the average stresses and the suction are not independent variables, but their work-conjugate strains $\varepsilon$ and $S_{r}$ are independent variables.

On the other hand, the choice of net stress and suction as the stress variables can be conveniently implemented into finite element codes working with total stresses. While it is true that most constitutive models for saturated soils are described in terms of effective stresses, these constitutive models can also be transferred to forms using total stress, pore water pressure and strains. Therefore, this formulation is equally well suited for finite element implementation (may be even better as it simplifies a few terms in the governing equations, comparing Olivella et al. (1994) and Sheng et al. (2003)). However, in the case when one has to work with existing codes for saturated soils where constitutive equations are formulated in effective stresses, difficulties may occur for transition between saturated and unsaturated states and a de-saturation suction may be required in the formulation. In the cases when the pore air pressure is absent, the constitutive equations for saturated states can not recover those for unsaturated states without additional control. It should also be noted that the net independent variables, but and $\varepsilon_{w}$ are not independent From the work input eq clear that there is no need to stress concept except the one stresses will not lead to sintprer stress-strain relations. In addition, such effective stresses often include a complex

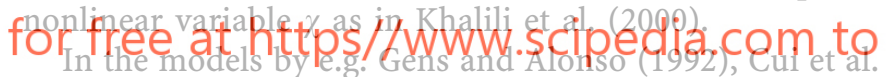
(1995), Wheeler and Sivakumar (1995), Alonso et al. (1999), Vaunat et al. (2000) and Buisson and Wheeler (2000), the net stresses and the suction are used as the stress variable, while the soil skeleton strain and the hydraulic strain are their work-conjugate strains, respectively. In the models by e.g. Jommi and Di Prisco (1994), Bolzon et al. (1996) and Wheeler et al. (2003), the average stress and the suction or the modified suction (the product of the porosity and suction) are used as the stress variables, while the soil skeleton strain and the degree of saturation are then the work-conjugate strain variables. Note that some of the earlier models do not use the complete work-conjugate stresses and strains.

In this paper, we adopt the following work-conjugate stresses and strains:

$$
\begin{aligned}
& \left(\begin{array}{c}
\boldsymbol{\sigma}^{\prime} \\
S
\end{array}\right)=\left(\begin{array}{c}
\boldsymbol{\sigma}-S_{r} u_{w}-\left(1-S_{r}\right) u_{a} \\
u_{a}-u_{w}
\end{array}\right) \\
& \left(\begin{array}{c}
\boldsymbol{\varepsilon} \\
S_{r}
\end{array}\right)
\end{aligned}
$$

The reason for using the suction $s$ instead of the modified suction $S^{\prime}=n s$ is that most experimental data use $s$ instead of $s^{\prime}$. Using $s^{\prime}$ does provide some advantage in the thermomechanical considerations of the model, but it is generally not necessary in deriving the constitutive equations, as will be shown in the following sections. There is no essential difference in these two stress quantities, as the porosity $n$ plays a role similar to a scaling parameter. The stresses defined in (3) are referred to as constitutive stresses in this paper, implying they are the stresses variables used in the constitutive equations. The constitutive stresses are the effective stresses for saturated states and the average or Bishop stresses for unsaturated states, respectively. The concept of 'effective stresses' for unsaturated states is avoided as they are no longer the only stress variables for unsaturated states. With this choice of stress and strain variables, all the equations described in this paper apply both to unsaturated and saturated states.

\section{2}

\section{Volumetric behaviour}

Slightly different from the modified Cam clay model (Roscoe and Burland, 1968) and the BBM (Alonso et al. 1990), we assume a linear relationship between logarithmic specific volume $\ln v$ and the logarithmic constitutive mean stress $\ln p^{\prime}$ at a given suction. Using a linear $\ln v-\ln p^{\prime}$ relationship instead of a linear $v-\ln p^{\prime}$ relationship is

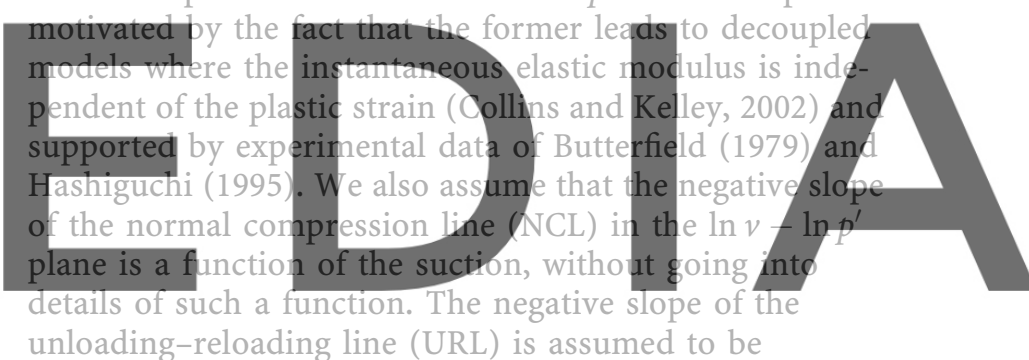

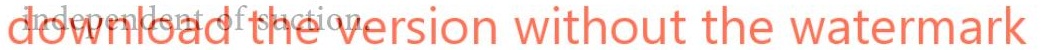

$$
\begin{aligned}
& \text { NCL : } \quad \frac{d(\ln v)}{d\left(\ln p^{\prime}\right)}=-\lambda_{\mathrm{s}} \\
& \text { URL : } \quad \frac{\mathrm{d}(\ln v)}{d\left(\ln p^{\prime}\right)}=-\kappa
\end{aligned}
$$

When a double-logarithmic relation is used, the finite logarithmic strain can be then conveniently used.

$\varepsilon_{\mathrm{v}}=\ln v_{0}-\ln v$

$\delta \varepsilon_{\mathrm{v}}=-\frac{\delta v}{v}$

Equations (4) and (5) also define the plastic volumetric strain under isotropic compression

$\mathrm{d} \varepsilon_{\mathrm{v}}^{\mathrm{p}}=\frac{\lambda-\kappa}{p^{\prime}} \mathrm{d} p^{\prime}$

\section{3}

\section{Hydraulic behaviour}

As pointed in the Introduction, an important feature of unsaturated soil behaviour is the irreversible changes in volume and degree of saturation caused by cyclic drying and wetting under constant net stress. According to Childs (1969), any cycle of drying and wetting has to be 
within two limiting curves obtained by drying from a fully saturated state and wetting from a very dry state, respectively. These two limiting curves are indicated by $\psi^{S I}$ and $\psi^{S D}$ in Fig. 1. Say, the initial state $\left(S_{r 0}-s_{0}\right)$ is at point A. Drying from point A will first follow an elastic line (scanning curve) until the suction reaches the main drying curve $\psi^{S I}$ at point B. Continued drying from point $\mathrm{B}$ will follow the elastoplastic main drying curve $\psi^{S I}$. If the soil is wetted at point $\mathrm{C}$ to the initial suction $s_{0}$, it will then follow the elastic scanning curve to point D. The difference in the degree of saturation between point $\mathrm{A}$ and $\mathrm{D}$ is due to the so-called hydraulic hysteresis. Similarly, the suction cycle from A to E, F and G also results in an irreversible change of degree of saturation. Therefore, for any unsaturated state in $S_{r}-s$ space, there exist two yielding stresses and they are coupled together through the relations between the main drying and wetting curves and the scanning curves. For example, the yielding stresses for the state at point $\mathrm{A}$ are the suctions at point B and E.

Without going to the details of the retention curves, we can write the general elastoplastic $S_{r}-s$ relation:

Main drying curve: $S_{\mathrm{r}}=\psi^{\mathrm{SI}}(s)$

Main wetting curve: $S_{\mathrm{r}}=\psi^{\mathrm{SD}}(s)$

The elastic $S_{r}-s$ relation is assumed to be linear:
Scanning curve: $\frac{\mathrm{d} S_{\mathrm{r}}}{\mathrm{d} s}=K_{\mathrm{s}}$
Equations (7), (8) and (9) also define the relation between
the plastic increment of $S_{r}$ and the suction:

$\mathrm{d} S_{\mathrm{r}}^{\mathrm{p}}=\left(\frac{\mathrm{d} \psi^{\mathrm{S} \alpha}}{\mathrm{d} s}-\frac{1}{K_{\mathrm{s}}}\right) \mathrm{d} s \quad \alpha=I, D$

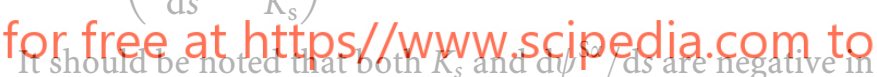
value. While the functions $\psi^{S \alpha}$ are not specified, there is one condition between $\psi^{S \alpha}$ and $K_{S}$ :

$\left.\frac{\partial \psi^{\mathrm{SI}}}{\partial s}\right|_{s=0} \leq \frac{1}{K_{\mathrm{s}}} \leq\left.\frac{\partial \psi^{\mathrm{SD}}}{\partial s}\right|_{s=0}$

This condition ensures that the scanning curves passing the points near the full saturation will still be inside the main drying and wetting curves.

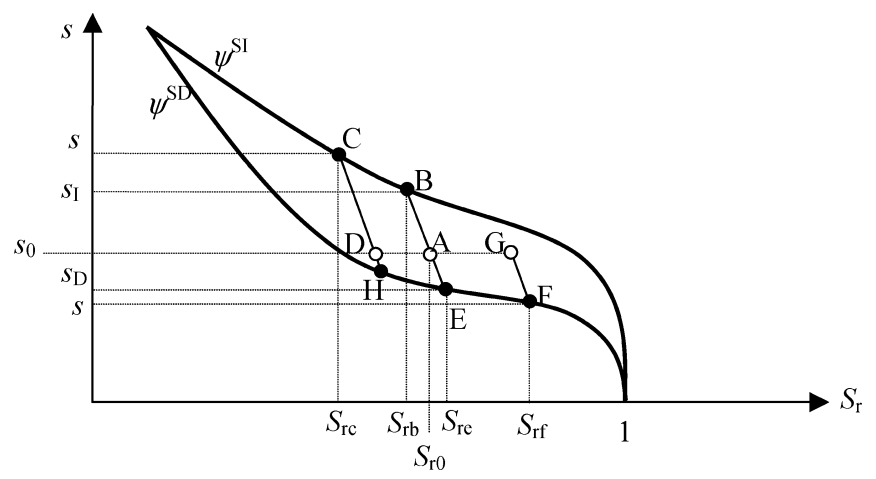

Fig. 1. Hydraulic behaviour under constant void ratio

\section{4}

\section{Yield functions}

With the volumetric and hydraulic behaviour defined, we can now construct the yield surface in the generalised stress space. For easier visualisation, we work with triaxial test stresses like the constitutive mean stress $p^{\prime}$, the deviator stress $q$, and the suction $s$. We assume that

1. The behaviour of saturated soil is represented by the modified Cam clay model (MCCM)

2. The elliptic yield surface of the MCC model is valid for suction $s>0$

3. The preconsolidation pressure $p_{c}^{\prime}$ is a function of suction

Such assumptions bear roots of the BBM, except that they hold in the space of net stresses and suction in the BBM. The elliptic yield surface inherited from the saturated soils is denoted by $f^{L C}$ referring to the load-collapse (LC) yield surface as in the BBM.

$f^{\mathrm{LC}} \equiv q^{2}-M^{2} p^{\prime}\left(p_{c}^{\prime}(s)-p^{\prime}\right)=0$

(12)

In the model by Wheeler et al. (2003), the LC yield surface is assumed to be independent of the modified suction $s^{\prime}$ in the constitutive stress space. While it can simply be achieved by setting $p_{c}^{\prime}$ independent of $s$ here, this simplification does lead to difficulty in modelling the collapse

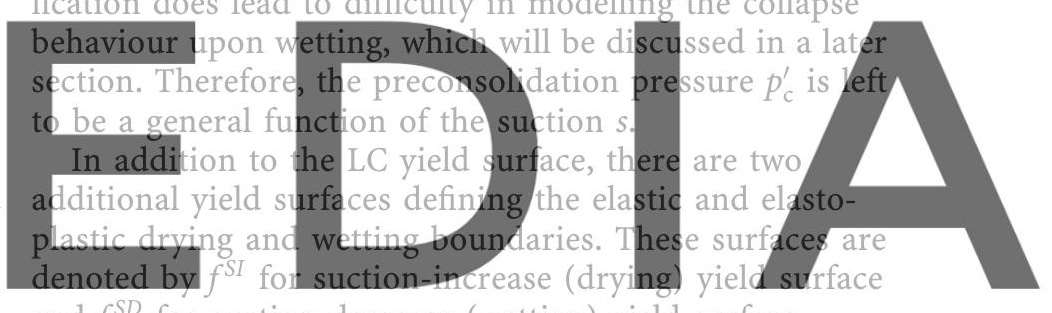
and $f^{S D}$ for suction-decrease (wetting) yield surface.

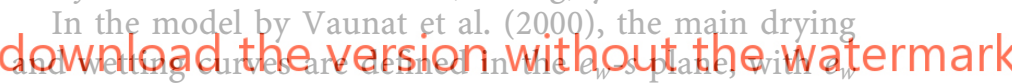
being the water ratio (water volume divided by solid volume). As the water ratio is a function of the initial void ratio, the main drying and wetting curves are dependent on the initial void ratio. As a result, the suction at the yielding point (e.g. points B and E in Fig. 1) will depend on the initial void ratio (i.e. at point A). As the initial void ratio can be affected by the mean stress (either net or constitutive), the yielding suction thus depends on the mean stress. In the models by Alonso et al. (1999) and Vaunat et al. (2000), the projections of the yield surfaces $f^{S D}$ and $f^{S I}$ in the $p^{\prime \prime}-s$ space are assumed to be inclined lines.

However, when the main drying and wetting curves are defined in the $S_{r}-s$ plane, it is reasonable to assume that they are unique for the same soil, irrespective of its initial void ratio. Therefore, we can assume that the yielding suction is independent of the initial void ratio and hence independent of the constitutive mean stress. Therefore, the projections of the yield surfaces $f^{S D}$ and $f^{S I}$ in the $p^{\prime}-s$ plane are horizontal lines and the yield surfaces can be represented by (Fig. 2)

$f^{\mathrm{SI}} \equiv s-s_{\mathrm{I}}=0$
$f^{\mathrm{SD}} \equiv s_{\mathrm{D}}-s=0$ 


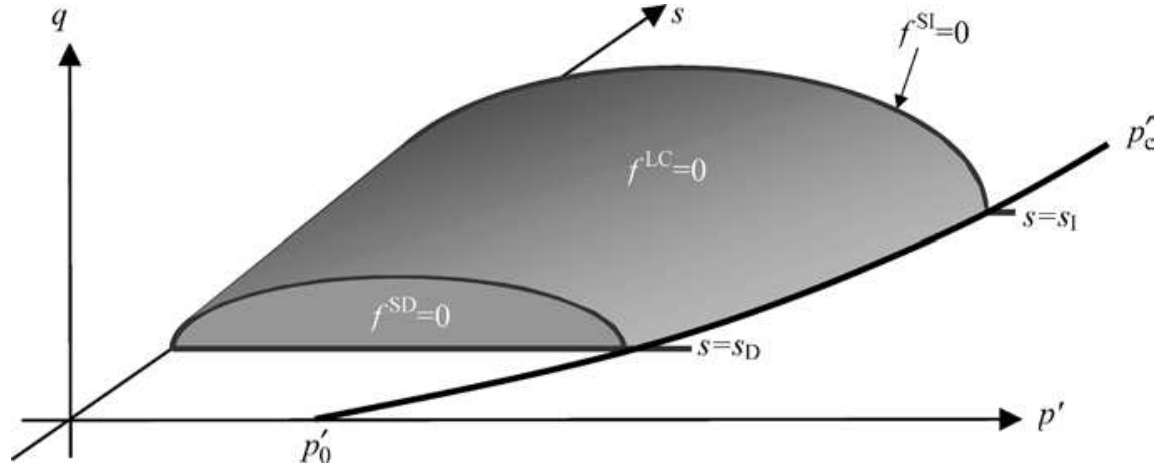

Fig. 2. Yield surfaces
457 where $s_{I}$ and $s_{D}$ are the yielding suctions for drying and wetting respectively.

\section{5}

\section{Plastic potentials}

For plastic potentials, we adopt the non-associated flow rule of the BBM for the load-collapse yield surface,

$g^{\mathrm{LC}} \equiv \zeta q^{2}-M^{2} p^{\prime}\left(p_{c}^{\prime}(s)-p^{\prime}\right)=0$

where $\zeta$ is a constant that can be determined by imposing zero lateral strains under $K_{0}$ stress conditions.

Alonso (1999), Vaunat e

(2003) used associated flow

(SI) and suction-decrease (SD

Buisson and Wheeler (2000)

flow rules be used with the $\mathrm{SI}$

associated flow rules for the

and (14) implies that a suction change inside the LC yield surface under constant constitutive mean stress will not cause any plastic volumetric strain. This is of course a

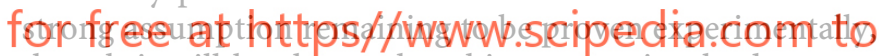
though it will be shown that this assumption leads to a thermomechanically conforming model. More generally,

we can use non-associated flow rules for the SI and SD yield surfaces and assume the plastic potentials take the following form:

$g^{\mathrm{SI}} \equiv s+a_{\mathrm{I}} p^{\prime}+b_{\mathrm{I}}=0$

$g^{\mathrm{SD}} \equiv-s-a_{\mathrm{D}} p^{\prime}-b_{\mathrm{D}}=0$

where parameters $a_{I}, a_{D}, b_{I}$ and $b_{D}$ are material parameters. Parameters $a_{I}$ and $a_{D}$ control the plastic volume behaviour upon drying and wetting respectively. Consider a reversible loop of drying and wetting, such as the one $\mathrm{A} \rightarrow \mathrm{B} \rightarrow \mathrm{C} \rightarrow \mathrm{D} \rightarrow \mathrm{H} \rightarrow \mathrm{E} \rightarrow \mathrm{F} \rightarrow \mathrm{A}$ in Fig. 1. Such a loop of drying and wetting under constant constitutive mean stress should not result in any plastic volumetric strain. Therefore, the two parameters $a_{I}$ and $a_{D}$ should be equal, i.e. $a_{I}=a_{D}=a$, and $a$ is referred to as the dilation ratio of suction of the soil. Parameters $b_{I}$ and $b_{D}$ will not be needed in the incremental stress-strain relations.

The plastic potentials of (16) and (17) give us some flexibility in simulating volumetric behaviour upon drying and wetting. For example, it is possible, using Eq. (17), to model both the softening caused by wetting for expansive soils and the hardening caused by wetting for collapsible soils. Setting $a$ to positive will result in plastic volume expansion upon wetting, which is observed for expansive soils. On the other hand, a negative $a$ will result in plastic volume shrinkage upon wetting, which is observed for collapsible soils. Since the load-collapse yield surface already covers the collapse feature of unsaturated soils, using a positive $a$ will be preferable. In this case, wetting can cause either elastoplastic collapse if the initial stress state is on or close to the LC yield surface, or elastoplastic expansion if the initial stress state is away from the LC yield surface. Therefore, the SD yield surface plays a similar role as the neutral loading (NL) yield surface in the conceptual

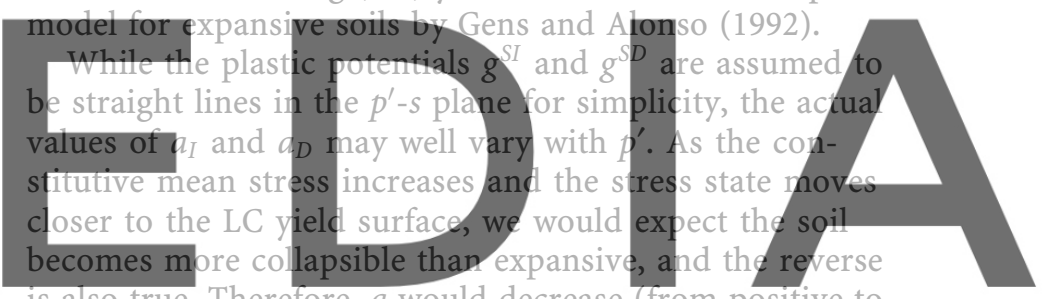
is also true. Therefore, a would decrease (from positive to zero) as $p^{\prime}$ increases. However, this type of relation will

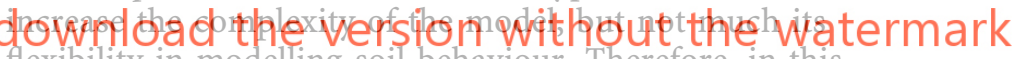
flexibility in modelling soil behaviour. Therefore, in this paper, we will limit out discussion to constant $a$ and assume $a>0$.

\section{6}

\section{Hardening laws}

As in the MCCM and BBM, we consider only isotropic hardening in this paper. The isotropic hardening laws can be derived from the volumetric and hydraulic behaviour. If the preconsolidation pressure $p_{c}^{\prime}$ is a known function of suction $s$, the evolution of the LC yield surface is fully controlled by the preconsolidation pressure $p_{0}^{\prime}$ at $s=0$. Taking $p_{0}^{\prime}$ as the hardening parameter for the LC yield surface, we have the following hardening law:

$\mathrm{d} p_{0}^{\prime}=\frac{p_{0}^{\prime}}{\lambda_{0}-\kappa} \mathrm{d} \varepsilon_{\mathrm{v}}^{\mathrm{p}}=\frac{p_{0}^{\prime}}{\lambda_{0}-\kappa}\left(M^{2}\left(-p_{\mathrm{c}}^{\prime}+2 p^{\prime}\right)\right) \mathrm{d} \lambda$

where $\mathrm{d} \lambda$ is a plastic multiplier and can be solved from the consistency condition $\mathrm{d} f^{L C}=0$. In the model by Wheeler et al. (2003), the hardening law for the LC yield surface is coupled to the yielding at the SI and SD yield surfaces. However, this coupling introduces two addition material parameters, but not additional flexibility in modelling the soil behaviour. Therefore, it is not considered in this paper. 
The evolution of the SI and SD yield surfaces is controlled by the yielding suction $s_{I}$ and $s_{D}$ respectively. Using Eq. (10), we have

$\mathrm{d} s_{\alpha}=\frac{\mathrm{d} s_{\alpha}}{\mathrm{d} S_{\mathrm{r}}^{\mathrm{p}}} \mathrm{d} S_{\mathrm{r}}^{\mathrm{p}}=\left(\frac{K_{\mathrm{s}}}{\frac{\mathrm{d} \psi^{\mathrm{s} \alpha}}{d s} K_{\mathrm{s}}-1}\right)\left(\mathrm{d} \lambda_{\alpha} \frac{\partial g^{\mathrm{S} \alpha}}{\partial s}\right) \quad \alpha=I, D$

where $\mathrm{d} \lambda_{\alpha}$ are plastic multipliers and can be solved from the consistency condition $\mathrm{d} f^{S \alpha}=0$.

Figure 3 gives a schematic view of possible evolution of the yield surfaces in the $p^{\prime}-s$ plane. For stress path A where the suction increases with the constitutive mean stress remaining constant, the yield surfaces SI and SD will move upwards to SI-A and SD-A, respectively. For stress path B where the suction decreases with the constitutive mean stress remaining constant, the yield surfaces SI and SD will move downwards to SI-B and SD-B, respectively. The LC yield surface remains unchanged for stress paths A and B. For stress path $\mathrm{C}$ where the constitutive mean stress increases with the constant suction, the LC yield surface expands to LC-C while the SI and SD yield surface remain unchanged. For stress path D where both the constitutive mean stress and the suction increase, the SI and SD yield surfaces will move upwards and the LC yield surface will expand.

Note that drying under con resented by the stress path $A$ $D$, as the suction change will mean stress $p^{\prime}$. Depending on functions $p_{c}^{\prime}(s)$ and $\psi^{\text {SI }}(s)$, dry may or may not cause plastic to the model.

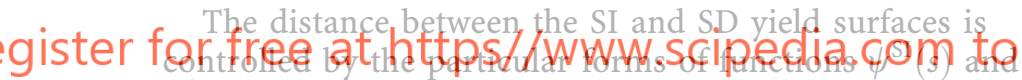
$\psi^{\mathrm{SD}}(\mathrm{s})$. As the saturation increases to 1 , this distance vanishes. Note that $p_{c}^{\prime}$ is independent of the pore water pressure once the soil becomes fully saturated. One consequence from this is the non-convexity of the LC yield surface at high degrees of saturation. This non-convexity is almost inevitable if $p_{c}^{\prime}$ increases with the suction. In fact, forcing the convexity of the LC yield surface in the

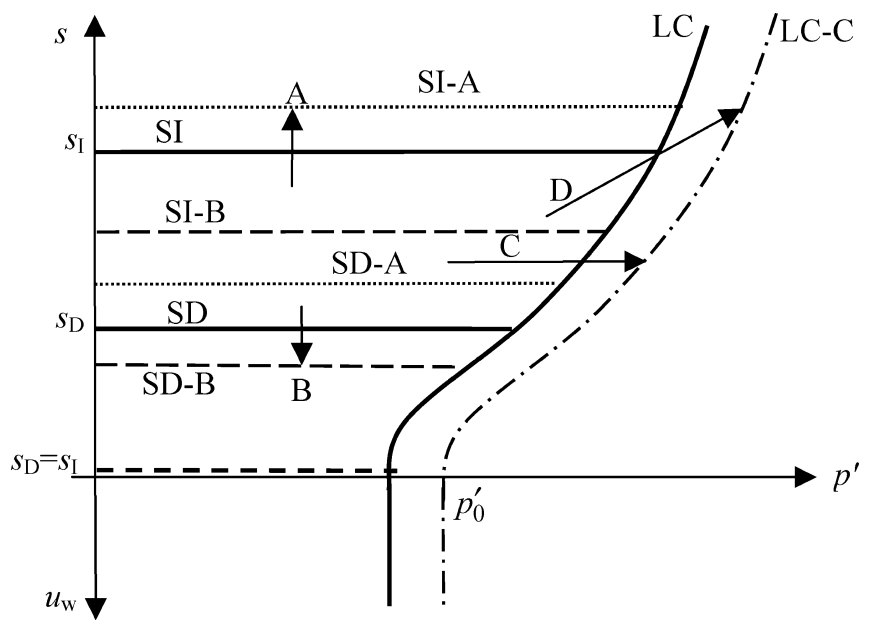

Fig. 3. Hardening under different stress paths unsaturated states will inevitably cause a discontinuity in the first order derivative of the yield surface at the transition point.

\section{7}

\section{Plastic multipliers}

The plastic multiplier in Eqs. (18) and (19) can be solved from the consistency conditions of the associated yield surfaces, which leads to

$\mathrm{d} \lambda=\frac{\mathbf{a}_{\mathrm{f}}^{\mathrm{T}} \mathbf{D}_{\mathrm{e}} d \varepsilon+C \mathrm{~d} s}{A+\mathbf{a}_{\mathrm{f}}^{\mathrm{T}} \mathbf{D}_{\mathrm{e}} \mathbf{a}_{\mathrm{g}}}$

where

$\mathbf{a}_{\mathrm{f}}=\frac{\partial f^{\mathrm{LC}}}{\partial \boldsymbol{\sigma}^{\prime}} \quad \mathbf{a}_{\mathrm{g}}=\frac{\partial g^{\mathrm{LC}}}{\partial \boldsymbol{\sigma}^{\prime}}$

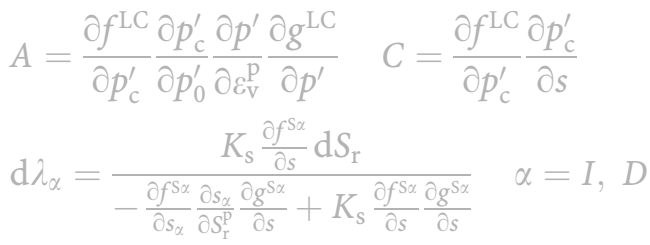

Note that due to the negative value of $K_{s}, d \lambda_{\alpha}$ is negative for a plastic increment of the degree of saturation. This implies that a suction increment $(d s>0)$ at the SI yield

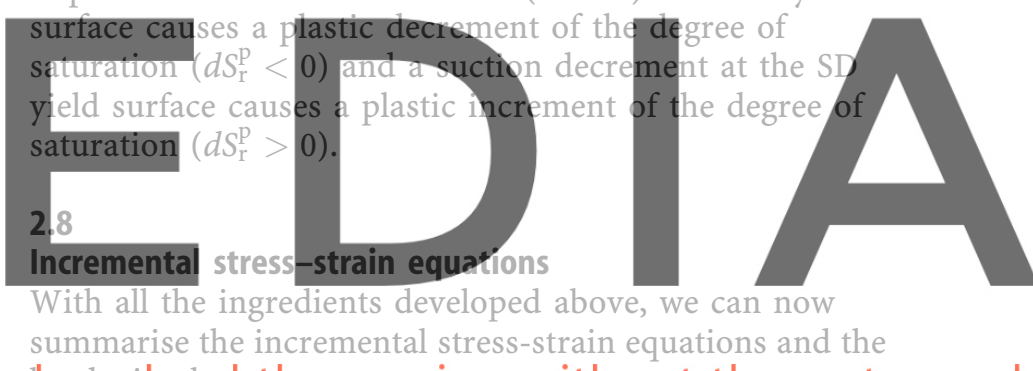
Whenental stress-strain equations and the charding ads:the version without the watermark $\mathrm{d} \sigma^{\prime}=\mathrm{D}_{\mathrm{e}}\left(\mathrm{d} \varepsilon-\mathrm{d}_{\varepsilon^{\mathrm{p}}}^{\mathrm{p}}\right)=\mathrm{D}_{\mathrm{ep}} \mathrm{d} \varepsilon+\mathrm{W}_{\mathrm{ep}} \mathrm{d} s$

$\mathrm{d} s=K_{\mathrm{s}}\left(\mathrm{d} S_{\mathrm{r}}-\mathrm{d} S_{\mathrm{r}}^{\mathrm{p}}\right)=\mathrm{G}_{\alpha} \mathrm{d} S_{\mathrm{r}}$

$\mathrm{d} \kappa=\mathrm{d} p_{0}^{\prime}=\mathbf{R}_{\mathrm{ep}} \mathrm{d} \boldsymbol{\varepsilon}+\mathrm{Q} \mathrm{d} s$

$\mathrm{d} \kappa=\mathrm{d} s_{\alpha}=\left(\frac{\mathrm{d} s_{\alpha}}{\mathrm{d} S_{\mathrm{r}}^{\mathrm{p}}} \frac{K_{\mathrm{s}}}{\mp \frac{\partial s_{\alpha}}{\partial S_{\mathrm{r}}^{\mathrm{p}}}+K_{\mathrm{s}}}\right) \mathrm{d} S_{\mathrm{r}} \quad \alpha=I, D$

where

$$
\begin{aligned}
& \mathbf{D}_{\mathrm{ep}}=\mathbf{D}_{e}-\frac{\mathbf{D}_{e} \mathbf{a}_{g} \mathbf{a}_{f}^{T} \mathbf{D}_{e}}{A+\mathbf{a}_{f}^{T} \mathbf{D}_{e} \mathbf{a}_{g}} \\
& \mathbf{E}_{\mathrm{ep}}=-\frac{\mathbf{D}_{e} \mathbf{a}_{g} C}{A+\mathbf{a}_{f}^{T} \mathbf{D}_{e} \mathbf{a}_{g}} \quad \mathbf{R}_{\mathrm{ep}}=B \frac{\mathbf{a}_{f}^{T} \mathbf{D}_{e}}{A+\mathbf{a}_{f}^{T} \mathbf{D}_{e} \mathbf{a}_{g}}
\end{aligned}
$$$$
Q=\frac{B C}{A+\mathbf{a}_{f}^{T} \mathbf{D}_{e} \mathbf{a}_{g}} \quad B=\frac{\partial p^{\prime} o \partial g^{L C}}{\partial \varepsilon_{v}^{p} \partial p^{\prime}}
$$

$G_{\alpha}=K_{s}\left(1-\frac{\mathrm{d} \lambda_{\alpha}}{\mathrm{d} S_{\mathrm{r}}} \frac{\partial g^{\mathrm{S} \alpha}}{\partial s}\right)$

$\frac{\mathrm{d} \lambda_{\alpha}}{\mathrm{d} S_{\mathrm{r}}}=\frac{K_{\mathrm{s}} \frac{\partial f^{\mathrm{s} \alpha}}{\partial s}}{-\frac{\partial f^{s \alpha}}{\partial s} \frac{\mathrm{d} s_{\alpha}}{\mathrm{d} s_{\mathrm{r}}^{\mathrm{p}}} \frac{\partial g^{s \alpha}}{\partial s}-K_{\mathrm{s}} \frac{\partial f^{s \alpha}}{\partial s} \frac{\partial g^{s \alpha}}{\partial s}} \quad \alpha=I, D$ 
$\frac{\mathrm{d} s_{\alpha}}{\mathrm{d} S_{\mathrm{r}}^{\mathrm{p}}}=\frac{K_{\mathrm{s}}}{\frac{\mathrm{d} \psi^{\mathrm{s \alpha}}}{\mathrm{d}_{s}} K_{\mathrm{s}}-1} \quad \alpha=I, D$

\section{9}

\section{Material parameters}

The model described above contains five material parameters and four material functions:

1. Frictional angle at critical state: $\phi^{\prime}$

2. Negative slope of NCL: $\lambda_{s}=\lambda(s)$

3. Intersection of $\operatorname{NCL}(s=0)$ when $p^{\prime}=1(\mathrm{kPa}): N$

4. Negative slope of URL: $\kappa$

5. Preconsolidation pressure: $p_{\mathrm{c}}^{\prime}=p_{\mathrm{c}}^{\prime}\left(p_{0, s}^{\prime} s\right)$

6. Elastic hydraulic constant: $K_{s}$

7. Main drying curve: $\psi^{S I}(s)$

8. Main wetting curve: $\psi^{S D}(s)$

9. Dilation ratio of suction: a

While it is not necessary to specify the material functions at this moment, it is worthwhile to mention some of commonly used ones for unsaturated soils. For example, the ones in the BBM of Alonso et al. (1990):

$\lambda_{\mathrm{s}}=\lambda_{0}((1-r) \exp (-\beta s)+r)$

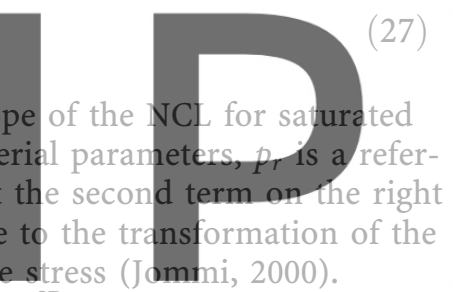

The functions $\psi^{\mathrm{SI}}(s)$ and $\psi^{\mathrm{SD}}(s)$ are suggested by

Romero and Vqunat (2000), based on the water retention

Compared to the BBM, the model presented here needs additional three material parameters $\left(K_{s}, a_{I}\right.$ and $\left.a_{D}\right)$ and one more constitutive function $\left(\psi^{S I}(s)\right.$ or $\left.\psi^{S D}(s)\right)$. Note that the BBM needs one soil-water characteristic function.

\section{3}

\section{Thermomechanical consideration}

While much of the physical or experimental evidence of the constitutive model presented in this paper can be found elsewhere (e.g. Gens and Alonso, 1992; Alonso, 1998; Romero and Vaunat, 2000), casting it against the basic thermomechanical principles can give us some insights of it.

\section{1}

\section{Total work input}

Neglecting the mechanical dissipation associated with fluid flows and the air compressibility, the incremental work input per unit volume of soil is

$\mathrm{d} W=\left(\boldsymbol{\sigma}^{\prime}\right)^{\mathrm{T}} \mathrm{d} \boldsymbol{\varepsilon}+n s \mathrm{~d} S_{\mathrm{r}}=\left(\boldsymbol{\sigma}^{\prime}\right)^{\mathrm{T}} \mathrm{d} \boldsymbol{\varepsilon}+\boldsymbol{s}^{\prime} \mathrm{d} S_{\mathrm{r}}$

Note that the porosity $n$ in the equation above is a function of the strain increment, but should be considered independent of the increment of the degree of saturation, because the work associated with the variation of the soil skeleton volume is already taken into account in the first term. This can also be understood by considering the strain increments $\mathrm{d} \varepsilon$ and the saturation increment $\mathrm{d} S_{r}$ as independent variables, or by using the modified suction concept $s^{\prime}$ by Wheeler et al. (2003).

\section{2}

\section{Plastic work increment and dissipation function}

The plastic component of the work increment is

$\mathrm{d} W^{\mathrm{p}}=\left(\boldsymbol{\sigma}^{\prime}\right)^{\mathrm{T}} \mathrm{d} \varepsilon^{\mathrm{p}}+n s \mathrm{~d} S_{\mathrm{r}}^{\mathrm{p}}$

For uncoupled materials whose instantaneous elastic modulus is independent of the plastic strain, the plastic work increment can be decomposed into two components (Collins and Hilder, 2002):

$\mathrm{d} W^{\mathrm{P}}=\mathrm{d} \Psi_{2}+d \Phi$

where $\Psi_{2}$ is the part of the Helmholtz free energy that depends only on plastic strains, d denotes the differential, and $d \Phi$ is the dissipation increment. The basic thermodynamical requirements on any constitutive model are that (a) the dissipation $d \Phi$ is strictly positive for any non-zero plastic strain, (b) the free energy $\mathrm{d} \Psi_{2}$ can be positive and negative, but gives zero when integrated over a closed loop of plastic strain.

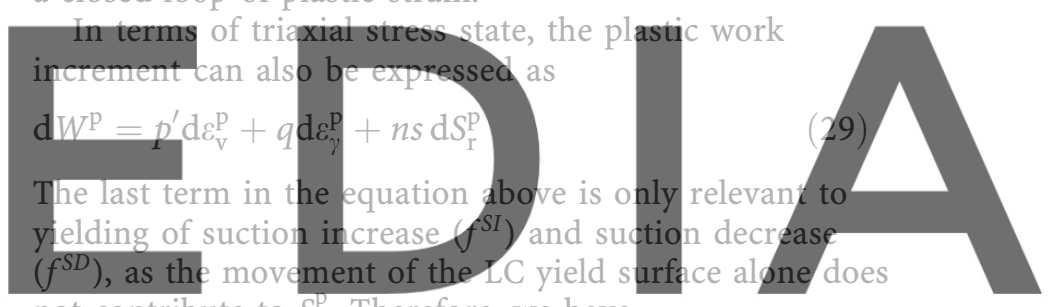

not contribute to $S_{\mathrm{r}}^{\mathrm{p}}$. Therefore, we have

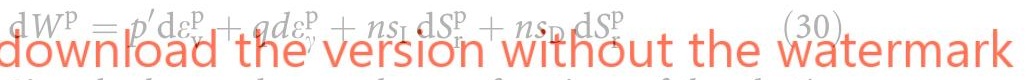
Since both $s_{I}$ and $s_{D}$ are known functions of the plastic increment of the degree of saturation and $n$ is independent of $d S_{\mathrm{r}}^{\mathrm{p}}$, the last two terms on the right-hand side of the equation above are integrable and give zero when integrated around a closed loop of $S_{\mathrm{r}}^{\mathrm{p}}$. These two terms hence belong to the free energy $\mathrm{d} \Psi_{2}$

To find the first two terms in Eq. (29) we first assume that plastic volumetric and distortional strains are solely caused by yielding at the LC yield surface. This assumption is equivalent to setting the dilation ratio of suction to zero $(a=0)$. In such a case we can use the LC yield function plastic potential to extend the first two terms in equation Eq. (29) as:

$$
\begin{aligned}
\mathrm{d} W^{\mathrm{p}}= & \left(\frac{1}{2} p_{\mathrm{c}}^{\prime} \mathrm{d} \varepsilon_{\mathrm{v}}^{\mathrm{p}}+n s_{\mathrm{I}} \mathrm{d} S_{\mathrm{r}}^{\mathrm{p}}+n s_{\mathrm{D}} \mathrm{d} S_{\mathrm{r}}^{\mathrm{p}}\right) \\
& +\left(\frac{1}{2} p_{\mathrm{c}}^{\prime} \frac{\left(\mathrm{d} \varepsilon_{\mathrm{v}}^{\mathrm{p}}\right)^{2}+\frac{M^{2}}{\zeta}\left(\mathrm{d} \varepsilon_{\gamma}^{\mathrm{p}}\right)^{2}}{\sqrt{\left(\mathrm{d} \varepsilon_{\mathrm{v}}^{\mathrm{p}}\right)^{2}+\frac{M^{2}}{\zeta^{2}}\left(\mathrm{~d} \varepsilon_{\gamma}^{\mathrm{p}}\right)^{2}}}\right)
\end{aligned}
$$

The terms in the first brackets are all integrable, as $p_{c}^{\prime}$ is a known function of $\mathrm{d} \varepsilon_{\mathrm{v}}^{\mathrm{p}}$, i.e. Eq. (6). These terms can be either positive or negative, but give zero when integrated around a closed loop of plastic strain. Therefore, they are the contribution to the plastic work from the free energy 
and hence are $\mathrm{d}_{2}$ The term in the second brackets is not integrable because it also involves the plastic shear strain. This term is hence the dissipation function $d \Phi$

$$
\begin{aligned}
& \mathrm{d} \Psi_{2}=\frac{1}{2} p_{\mathrm{c}}^{\prime} \mathrm{d} \varepsilon_{\mathrm{v}}^{\mathrm{p}}+n s_{\mathrm{I}} \mathrm{d} S_{\mathrm{r}}^{\mathrm{p}}+n s_{\mathrm{D}} \mathrm{d} S_{\mathrm{r}}^{\mathrm{p}} \\
& \mathrm{d} \Phi=\frac{1}{2} p_{\mathrm{c}}^{\prime} \frac{\left(\mathrm{d} \varepsilon_{\mathrm{v}}^{\mathrm{p}}\right)^{2}+\frac{M^{2}}{\zeta}\left(\mathrm{d} \varepsilon_{\gamma}^{\mathrm{p}}\right)^{2}}{\sqrt{\left(\mathrm{d} \varepsilon_{\mathrm{v}}^{\mathrm{p}}\right)^{2}+\frac{M^{2}}{\zeta^{2}}\left(\mathrm{~d} \varepsilon_{\gamma}^{\mathrm{p}}\right)^{2}}} \geq 0
\end{aligned}
$$

The dissipation function (32) is obviously strictly positive whenever the plastic strains are non zero, as required by the second law of thermodynamics. It can also be shown that the dissipation function above is a homogeneous function of degree 1 in the plastic strain increments, as it is required. Please also note that this dissination function is valid for the original BBM.

Equations (31) and (32) indicate that the plastic yielding at the suction-increase and suction-decrease yield surfaces does not contribute to the plastic dissipation, but only to the plastic work. This means that all plastic work associated with a plastic increment of degree of saturation (e.g. the plastic work done during path $\mathrm{ABCD}$ in Fig. 1) is stored and can be recovered during a reversed plastic increment of saturation (e.g. the plastic work released during path DHEA in Fig. 1). This is piastic work is very
much the same as the 'locked in elastic encrgy' due to the
shift or back stress (Collins and Hilder, 2002).
The fact that the dissipation function does not involve
the plastic increment of the degree of saturation 2 so
confirms that the SI and SD yield functions
$f^{S \alpha} \equiv \pi=s-c=0 \quad \alpha=T-$

where $c$ can be interpreted as a shift or back suction, and $\pi$

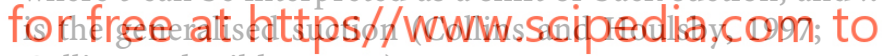
Collins and Hilder, 2002)

$\pi=\frac{\partial(\mathrm{d} \Phi)}{\partial\left(\mathrm{d} S_{\mathrm{r}}^{\mathrm{p}}\right)}$

Equation (33) is of course exactly of the same form as Eqs. (13) and (14)

In the case when a non-associated flow rule is used with the suction- increase and decrease yield surfaces $(a \neq 0)$, any plastic increment in the degree of saturation will also cause a plastic volumetric strain. Therefore, the first term $p^{\prime} \mathrm{d} \varepsilon_{\mathrm{v}}^{\mathrm{p}}$ in Eq. (29) will also have a contribution from the SI and SD yield functions. In such a case, we can no longer derive the free energy $\mathrm{d}_{2}$ and dissipation $\mathrm{d} \Phi$ that satisfy the basic thermodynamic requirements. However, it is possible to demonstrate that, under constant $p^{\prime}$, the contribution to $p^{\prime} \mathrm{d} \varepsilon_{\mathrm{v}}^{\mathrm{p}}$ from the SI and SD yielding contributes only to the free energy $\mathrm{d} \Psi_{2}$ during a closed loop of $S_{\mathrm{r}}^{\mathrm{p}}$.

\section{4}

Reformulation for displacement finite elements

In conventional finite element codes, the displacements and pore pressures are first solved at nodal points. The strains at integration points are then solved from the displacements. In order to follow this structure, the incremental stress-strain relations are conveniently rearranged as

$\mathrm{d} \boldsymbol{\sigma}^{\prime}=\mathbf{D}_{\mathrm{ep}} \mathrm{d} \boldsymbol{\varepsilon}+\mathbf{W}_{\mathrm{ep}} \mathrm{d} s$

$\mathrm{d} S_{\mathrm{r}}=\frac{1}{G_{\alpha}} \mathrm{d} s$

In the above equations, the suction is actually treated as a 'strain' variable and the degree of saturation is treated as a 'stress' variable. This exchange of roles also requires a corresponding change of the hardening parameters. Now let us work with 'stress' space $\left\{\boldsymbol{\sigma}^{\mathrm{T}} S_{\mathrm{r}}\right\}^{\mathrm{T}}$ and the yield surfaces $f^{S I}$ and $f^{S D}$ defined as:

$f^{S I} \equiv S_{r}-S_{r}^{I}=0$

$f^{\mathrm{SD}} \equiv S_{r}^{\mathrm{D}}-S_{r}=0$

Now treating $S_{\mathrm{r}}^{\mathrm{I}}$ and $S_{\mathrm{r}}^{\mathrm{D}}$ as the hardening parameter, we can derive the following hardening laws for the evolution of the suction-increase (or saturation-decrease) and suctiondecrease (or saturation-increase) yield surface:

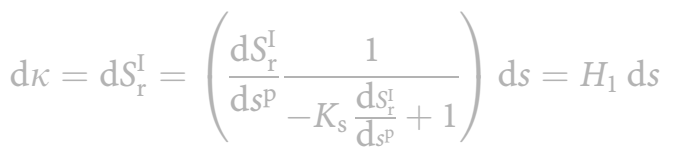
(36)
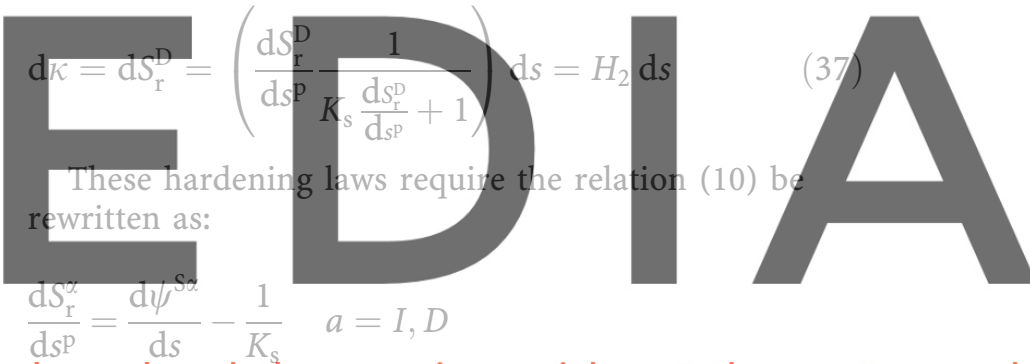

\section{downdoad the version without the wistisatermark}

Fig. 4. Now we consider a closed loop of the degree of saturation instead of a closed loop of suction. Drying from initial $S_{r 0}$ at point A to point B is purely elastic. The degree of saturation at point B is the yielding saturation $S_{r}^{\mathrm{I}}$, while the degree of saturation at point $\mathrm{F}$ is the yielding saturation $S_{\mathrm{r}}^{\mathrm{D}}$. The plastic increment of suction for the loop $\mathrm{ABCDE}$ is the $\left(s_{e}-s_{0}\right)$.

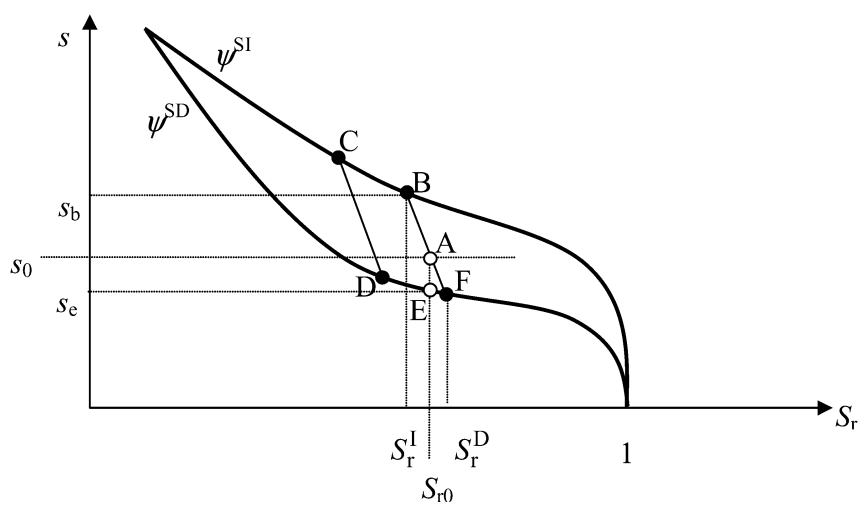

Fig. 4. Hydraulic behaviour under constant void ratio (a loop of saturation) 
The hardening law for the evolution of the load-collapse yield surface remains unchanged:

$\mathrm{d} \kappa=\mathrm{d} p_{0}^{\prime}=\mathbf{R}_{\mathrm{ep}} \mathrm{d} \boldsymbol{\varepsilon}+Q \mathrm{~d} s$

Equations (34)-(38) are a set of nonlinear ordinary differential equations that can be solved for the increments of stresses and degree of saturation given the increments in strains and suction. In order to simplify the expression, it is convenient to introduce the extended stresses, strains and hardening parameters:

$$
\begin{aligned}
& \mathrm{d} \tilde{\boldsymbol{\sigma}}=\left(\begin{array}{l}
\mathrm{d} \sigma^{\prime} \\
\mathrm{d} S_{\mathrm{r}}
\end{array}\right) \\
& \mathrm{d} \tilde{\boldsymbol{\varepsilon}}=\left(\begin{array}{l}
\mathrm{d} \varepsilon \\
\mathrm{d} s
\end{array}\right)
\end{aligned}
$$

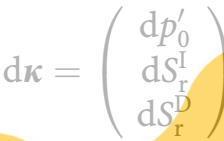

We can then rewrite Eqs. (34)-(38) follows

$\mathrm{d} \tilde{\boldsymbol{\sigma}}=\tilde{\mathrm{D}}_{\text {ep }} \mathrm{d} \tilde{\varepsilon}$

$\mathrm{d} \boldsymbol{\kappa}=\tilde{\mathbf{R}}_{\mathrm{ep}} \mathrm{d} \varepsilon$
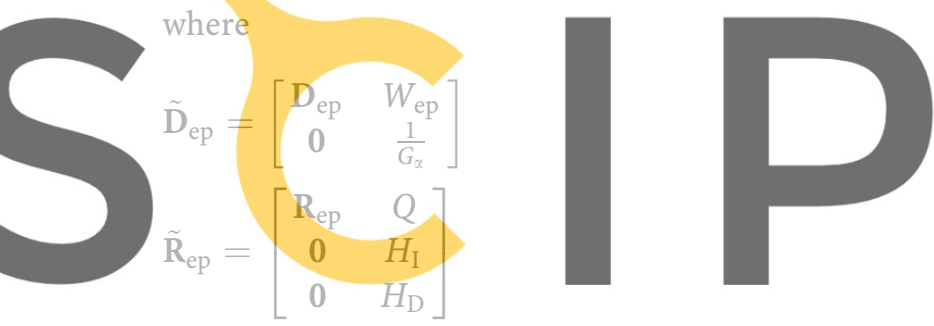

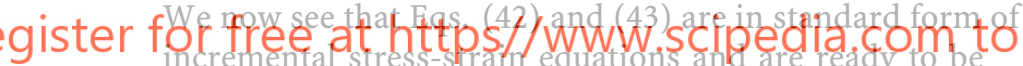

implemented into coupled displacement and pore pressure finite element method (Sheng and Sloan, 2003). In theory, these equations can be solved by a wide range of explicit and implicit integration schemes. However, with consideration of the complexity of the model (non-convexity and vertices in the yield surface), explicit schemes that evaluate the gradients of the yield surface and plastic potential and hardening laws at known stress states and require no iteration are likely to be more robust than implicit schemes that evaluate the gradients and hardening laws at unknown stress states and require iterations to solve the resulting nonlinear equations. Explicit schemes are also generally faster than implicit schemes, due to their non-iterative feature. In addition, they are simpler to implement, without the need of evaluation of the second order derivatives of the plastic potentials. The accuracy of explicit schemes, which is often perceived as their weak point, can be significantly improved by implementing automatic substepping and error control techniques (Sloan, 1987; Sloan et al. 2001; Sheng et al. 2003).

Note that, due to the non-convexity of the yield surface, a stress increment that starts and ends inside the yield surface may still cross the yield surface and possibly crosses it more than once (Fig. 5). This will require special treatment in an explicit scheme when locating the inter-

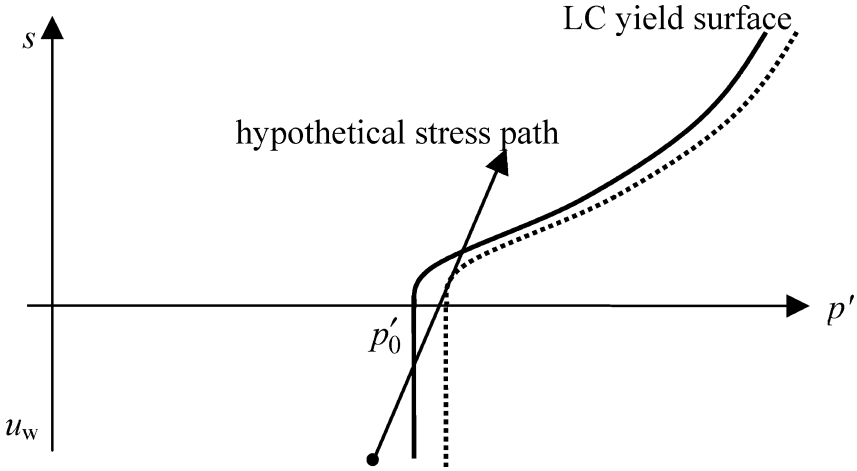

Fig. 5. A stress path that crosses the load-collapse yield surface twice

section points between the current yield surface and the elastic trial stress increments. Implicit schemes are likely to have convergence problems for such a stress path.

\section{5}

\section{Qualitative prediction}

While quantitative predictions of the model require the implementation into finite element codes, useful qualitative predictions can be derived directly from the model.

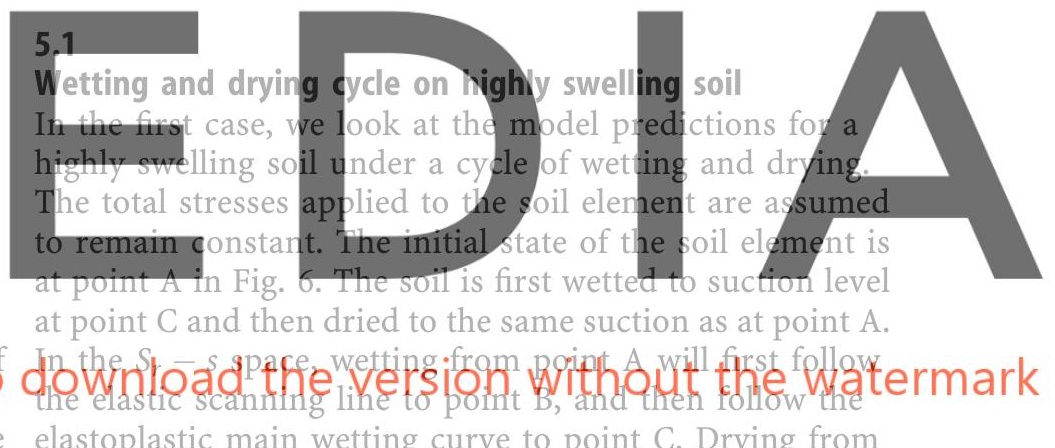

elastoplastic main wetting curve to point C. Drying from point $\mathrm{C}$ follows the elastic line to point $\mathrm{E}$ where the suction is the same as at point $\mathrm{A}$.

In the space of the constitutive mean stress versus the suction, ie the $p^{\prime}-\mathrm{s}$ space, wetting under constant total mean stress causes a decrease in the constitutive mean stress $p^{\prime}$, and drying under constant total mean stress causes an increase in the constitutive mean stress $p^{\prime}$. The initial stress state at point A is inside the LC yield surface and between the SI and SD yield surfaces. Wetting from point $A$ to point $B$ is purely elastic and causes a small amount of elastic volume expansion due to the decrease of the constitutive mean stress. Continued wetting from point $B$ to point $C$ will cause the downward movement of the SI and SD yield surfaces and hence plastic change of the degree of saturation. If the dilation ratio of suction $a$ is positive ( $a$ $>0$ ), wetting from $B$ to $C$ will cause plastic volume expansion in addition to the elastic volume expansion caused by decreased $p^{\prime}$. If the soil element is then dried at point $C$ to the same suction level at point $A$, the stress path in the $p^{\prime}-s$ space will not follow CBA, but CE. This is $p^{\prime}-s$ because the plastic increment of the degree of saturation between point $B$ and $C$ results in an increase in the constitutive mean stress from point $A$ to point $\mathrm{E}$. The LC yield surface remains unchanged during the cycle of wetting and drying. 

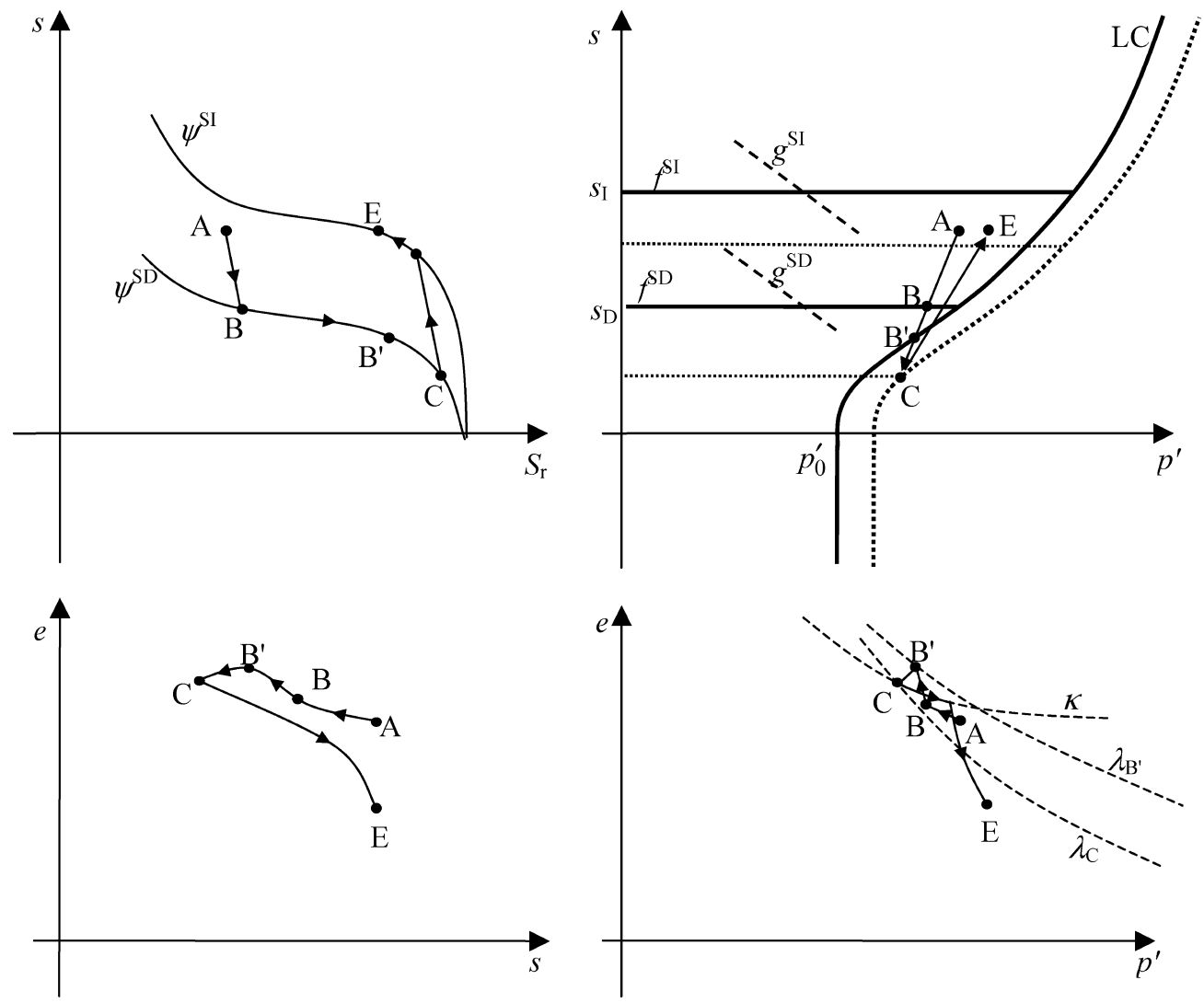

Fig. 7. Plastic volume decrease caused by a cycle of wetting and drying

the drying path CE first follows the unload-reloading line and then a significant decrease in the void ratio occurs after the stress path reaches the SI yield surface. In the $s-e$ space, the model predicts a peak void ratio-during the wetting path and a net volume decrease (irreversible shrinkage), during the closed loop of suction change. The curve $\mathrm{ABB}^{\prime} \mathrm{CE}$ in the $s-e$ space is consistent with the results reported by Alonso et al. (1995).

\section{3}

\section{Load-collapse of unsaturated soils}

As the presented model is built upon the BBM, it naturally inherits its capability of predicting collapse behaviour under isotropic compression and under wetting. This behaviour is shown in Fig. 8, where the soil element is first isotropically compressed under constant suction (ABC) and then wetted to a full saturation (CE). While the model predicts the same volume decrease caused by isotropic compression as the $\mathrm{BBM}$, it predicts a smaller volume decrease caused by wetting than the BBM. This is because the suction softening associated with the SD yield surface somewhat offsets the suction hardening associated with the LC yield surface. Note that during the wetting path $C^{\prime} E$, the SD and SI yield surfaces move downwards, with the latter moving faster. The distance between the two surfaces approaches zero when the soil becomes fully saturated at point E. Of course, setting $a=0$ in the presented model recovers the volumetric behaviour of yielding at the loadcollapse yield surface as the Barcelona Basic model, but still predicting the irreversible change in the degree of saturation upon wetting.
In the model by Wheeler et al. (2003), the LC yield surface is assumed to be independent of the modified suction $s^{\prime}$, i.e. a vertical straight line in the $p^{\prime}-s^{\prime}$ space. The normal compression line in the $p^{\prime}-e$ space is then unique. To model the collapse behaviour during the wetting path $\mathrm{CE}$, the constitutive mean stress would have to increase. This is again a strong assumption and does not agree with the wetting stress path proposed by Wheeler et al. (2003).

\section{6}

\section{Conclusions}

A constitutive model for unsaturated soils is presented. The model takes into account hydraulic hysteresis and the irreversible deformation during cyclic drying and wetting. All necessary ingredients for implementing the model into finite element codes are presented. A standard form of incremental stress-strain relations is derived. The constitutive model is then cast into the thermodynamical theories and verified using the thermomechanical principles. The incremental constitutive equations are also reformulated for implementation in finite element codes where displacements and pore pressures are primary unknowns.

Some key conclusions that can be drawn from this study are:

1. While any adequate set of work-conjugate stresses and strains can be used in constitutive modelling of unsaturated soils, the choice of the stress and strain variables can affect the implementation of the model into existing finite element codes. 

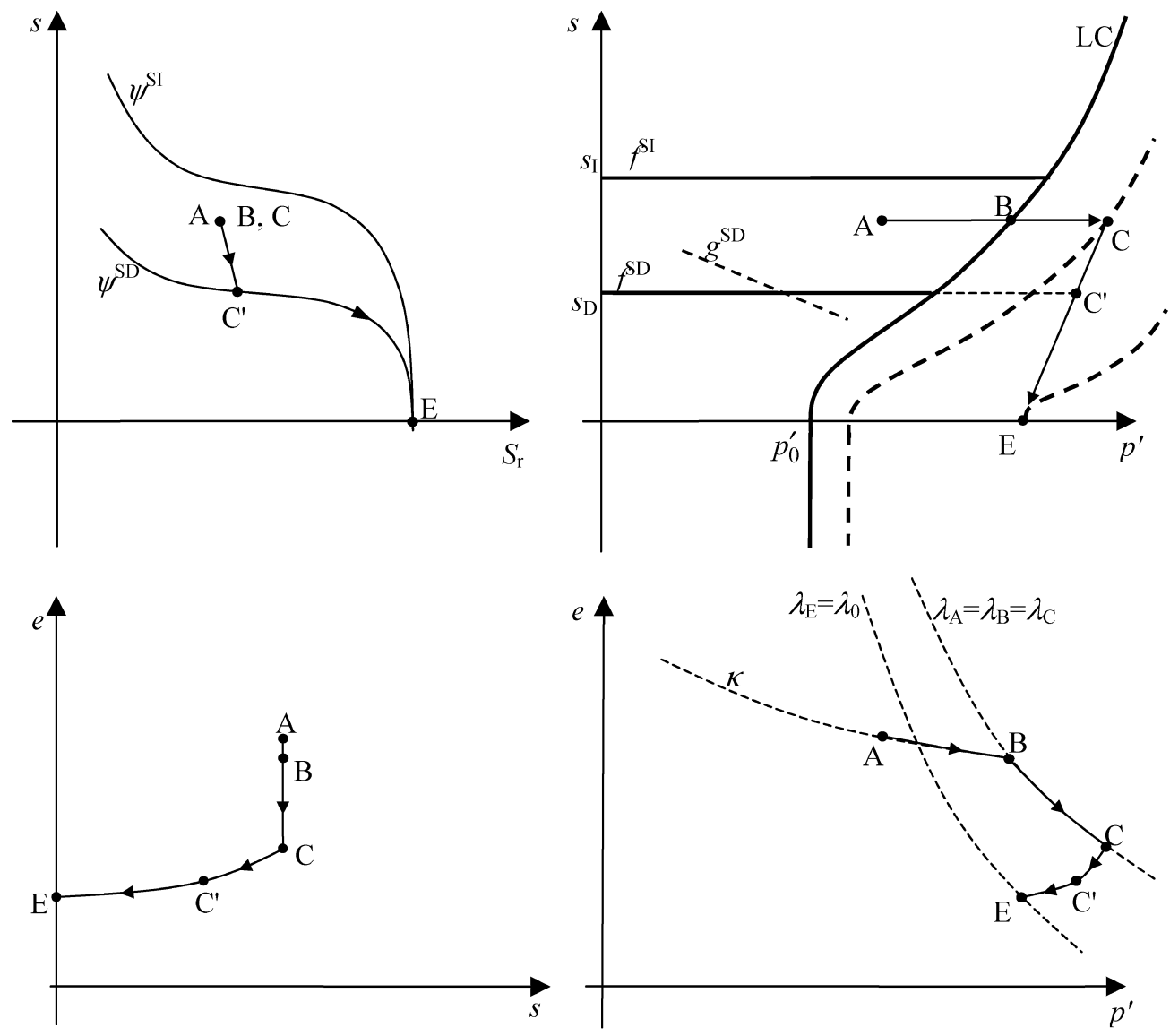

Fig. 8. Collapse due to isotropic loading and wetting

2. Incorporating two suction related yield surfaces and non-associated flow rules into the BBM opens a full range of possibilities in modelling unsaturated soil behaviour. Behaviour like hydraulic hysteresis and the plastic volume change during cyclic drying and wetting can thus be modelled within the same framework.

3. The constitutive model presented here satisfies the basic requirements of thermo-mechanical principles. The plastic dissipation function and the plastic work of the model are derived.

4. Hydraulic hysteresis does not contribute to the plastic dissipation, though it contributes to the plastic work. All plastic work associated with a plastic increment of degree of saturation is stored and can be recovered in a reversed plastic increment of saturation.

5. For finite element codes that use the displacements and pore pressures as primary variables, the incremental relations between the generalised stresses and strains are by nature in a mixed form. However, they can be transformed to a purely strain-driven format by exchanging the role of suction and the degree of saturation.

6. Due to the non-convexity and vertices of the yield surfaces, it is suggested that the incremental stress-strain relations should be solved using explicit integration methods.

7. Qualitative predictions of the model show that it can to reproduce a number of important features of unsaturated soils including expansive clays.

These features include irreversible swelling upon wetting and irreversible shrinkage upon drying for expansive soils, irreversible shrinkage upon wetting and a peak void ratio during wetting for collapsible soils, hydraulic hysteresis, load-dependency of swelling and collapse, etc.

\section{References}

Alonso EE (1998) Modelling expansive soil behaviour. In: proc. 2nd int. conf. on unsaturated soils, Beijing, International Academic Publishers, vol. 2, pp. 37-70

Alonso EE, Gens A, Gehling WYY (1994) Elastoplastic model for unsaturated expansive soils. In: Proc. 3rd european conf. on numerical methods in geotechnical engineering, Manchester, pp. $11-18$

Alonso EE, Gens A, Hight DW (1987) Special problem soils. General report. In: Proc. 9th european conf. on soil mechanics and foundation engineering, Dublin, vol 3, pp. 1087-1146

Alonso EE, Gens A, Josa A (1990) A constitutive model for partially saturated soils. Geotechnique 40(3): 405-430

Alonso EE, Vaunat J, Gens A (1999) Modelling the mechanical behaviour of expansive clays. Eng. Geol. 54: 173-183

Alonso EE, Yang DQ, Lloret A, Gens A (1995) Experimental behaviour of highly expansive double structure clay. In: Proc. 1 st int. conf. on unsaturated soils, Paris, Balkema, Rotterdam, vol. 1, pp. 11-16

Bolzon G, Schrefler BA, Zienkiewicz OC (1996) Elastoplastic soil constitutive laws generalized to semisaturated states. Géotechnique 46(2): 279-289

Buisson MSR, Wheeler SJ (2000) Inclusion of hydraulic hysteresis in a new elastoplastic framework for unsaturated soils. Experimental evidence and theoretical approaches in unsaturated soils. In: proc. of int. workshop on unsaturated soil, Trento, Italy, Balkema, Rotterdam, pp. 109-119 
Butterfield RA (1979) Natural compression law of soils (an advance on e-log $\mathrm{p}^{\prime}$ ). Geotechnique 29: 469-480

Childs EC (1969) An introduction to the physical basis of soil water phenomena. John Wiley \& Sons Ltd, London

Chu TY, Mou CH (1973) Volume change characteristics of expansive soils determined by controlled suction tests. In: proc. 3rd int. conf. on expansive soils. Haifa, vol. 1, pp. $177-185$

Collins IF, Hilder T (2002) A theoretical framework for constructing elastic/plastic constitutive models of triaxial tests. Int. J. Numer. Anal. Meth. Geomech. 26: 1313-1347

Collins JF, Houlsby GT (1997) Application of thermomechanical principles to modelling of geotechnical materials. Proc. Royal Soc. London A 453: 1975-2001

Collins IF, Kelley PA (2002) A thermomechanical analysis of a family of soil models. Geotechnique 52(7): 506-518

Cui YJ, Delage P, Sultain N (1995) An elasto-plastic model for compacted soils. In: proc. 1st int. conf. on unsaturated soils, Paris, Balkema, Rotterdam, vol. 2, pp. 703-709

Gens A (1996) Constitutive modelling: Application to compacted soils. In: proc. 1st int. conf. on unsaturated soils, Paris, Balkema, Rotterdam, vol. 3, pp. 1179-1200

Gens A, Alonso EE (1992) A framework for the behaviour of unsaturated expansive clays. Canadian Geotech. J. 29: 1013-1032

Gens A, Alonso EE, Josa A (1989) Elastoplastic modelling of partially saturated soils. In: proc. 3rd int. sym. on numerical models in geomechanics (NUMOG), Niagara Falls, pp. $163-170$

Hashiguchi K (1995) On the linear relations of $v-\ln p$ and $\ln v-\ln$ $p$ for isotropic consolidation of soils. Int. J. Numer. Analy. Meth. Geomech. 19: 367-376

Houlsby GT (1979) The work input to a granular material. Geotechnique. 29(3): 354-358

Houlsby GT (1997) The work input to an unsaturated granular material. Geotechnique 47(1): 193-196

Jommi C (2000) Remarks on constitutive modelling of unsaturated soils. In: Experimental evidence and theoretical approaches in unsaturated soils, proc. of int. workshop on unsaturated soil, Trento, Italy, Balkema, Rotterdam, pp. 139-153

Jommi C, di Prisco C (1994) Un semplice approccio teorico per la modellazione del comportamento meccanico dei terreni granulari parzialmente saturi. In: proc. of the conference on the role of fluids in geotechnical engineering problems, Mondovì, part 1 , pp. $167-188$
Khalili N, Khabbaz MH, Valliappan S (2000) An effective stress based numerical model for hydro-mechanical analysis in unsaturated porous media. Comput. Mech. 26(2): 174-184

Romero E, Vaunat J (2000) Retention curves of deformable clays. experimental evidence and theoretical approaches in unsaturated soils, proc. of int. workshop on unsaturated soil, Trento, Italy, Balkema, Rotterdam, pp. 91-106

Roscoe KH, Burland JB (1968) On the generalised stress-strain behaviour of wet clay. In: Engineering plasticity, (Heyman J, Leckie F (eds), Cambridge University Press, Cambridge, pp. $535-560$

Sanavia L, Schrefler BA, Steinmann P (2002) A formulation for an unsaturated porous medium undergoing large inelastic strains. Comput. Mech. 28(2): 137-151

Shen Z (1998) Advances in numerical modelling of deformation behaviour of unsaturated soils. In: Proc. 2 nd int. conf. on unsaturated soils, Beijing, International Academic Publishers, vol. 2, pp. 180-193

Sheng D, Sloan SW (2003) Time stepping schemes for coupled displacement and pore pressure analysis. Comput. Mech. 31: 122-134

Sloan SW (1987) Substepping schemes for the numerical integration of elastoplastic stress-strain relations. Int. J. Numer. Meth. Eng. 24(5): 893-911

Sloan SW, Abbo AJ, Sheng D (2001) Refined explicit integration of elastoplastic models with automatic error control. Eng. Comp. 18: 121-154

Vaunat J, Romero E, Jommi C (2000) An elastoplastic hydromechanical model for unsaturated soils. In: Experimental evidence and theoretical approaches in unsaturated soils, proc. of int. workshop on unsaturated soil, Trento, Italy, Balkema, Rotterdam, pp. 121-138

van Genuchten MTh (1980) A closed-form equation for predicting the hydraulic conductivity of unsaturated soils. Soil Sci. Soc. Am. J. 44: 892-898

Wheeler SJ (1996) Inclusion of specific water volume within an elastoplastic model for unsaturated soils. Canadian Geotech. J. 33: $42-57$

Wheeler SJ, Karube D (1996) Constitutive modelling. In: proc. 1st int. conf. on unsaturated soils, Paris, Balkema, Rotterdam, vol. 3, pp. 1323-1356

Wheeler SJ, Sharma RS, Buisson MSR (2003) Coupling of hydraulic hysteresis and stress-strain behaviour in unsaturated soils. Geotechnique 53(1): 41-54

Wheeler SJ, Sivakumar V (1995) An elasto-plastic critical state framework for unsaturated soil. Geotechnique 45(1): 35-53 